\title{
CrimRxiv
}

\section{Criminal Futures: \\ Predictive Policing and Everyday Police Work}

Simon Egbert, Matthias Leese

Published on: Dec 15, 2020

License: Creative Commons Attribution 4.0 International License (CC-BY 4.0). 
